\title{
Application of Intelligent Power Service System in Power Marketing
}

\author{
Chao Shang, Yuan Tian, Jiwen Yu and Yongchao Luo
}

\author{
State Grid Jiangxi Electric Power Research Institute, Jiangxi Nanchang 330096
}

Keywords: Intelligent power; Power service; System design; Information sharing platform.

\begin{abstract}
With the development of intelligent technology, the demand of diversified, personalized and interactive services increases sharply. Intelligent power service has been the inexorable trend of the development of power service. The traditional power service mode will be gradually replaced by new intelligent power service mode, but the existing power service system cannot meet the requirement of intelligent power service. However, it is a better choice to develop and design intelligent power service system. The communication network of intelligent power service system is designed, and remote and local access solutions in communication network are provided in this article. In addition, this article explain the safety guarantee system in intelligent power service system and design the users identity authentication and permission management system.
\end{abstract}

\section{Introduction}

With the development of intelligent grid, an integrated and invaluable social public platform will be established by the integration of energy flow and information flow brought by the integration of smart grid, internet of thins and internet. Establishment of the platform will cause drastic changes in the functions of grid and bring influence with big extent and significant degree to the future society. Intelligent power service system has great significance for increasing power service level, be a big choice of meeting the requirement of social and economic sustainable development and be the specific practice of the scientific development of electric power industry.

Intelligent power service system not only can fully make use of power grid resource in both urban and rural areas, high speed power communication resource and abundant business information resource but also can meet the requirement of diversified, personalized and interactive power services of users, thus build a totally new service platform, spread range of services and create more social value and economic benefits.

\section{Intelligent Power Service System}

Intelligent power service system is an integrated platform based on the integration of many system platforms such as marketing business application, power information collection, diversified payment, SMS platform, customer service, marketing, intelligent park and intelligent community, and which can meet all the requirements of users for intelligent power service by the integration of business flow, information flow and data flow and the combing and reformation for marketing business flow. The appropriate amount of quantitative trading is implemented before the purchasing event of users, and real time monitoring is implemented in the whole process of providing service to provide more convenient and efficient service for users by intelligent power service system.

Service support and service requirement of power supplier and users communicate with diversified services and dispatching platform. The system collect the real time monitoring site information and provide power on/off service by remote control function according to dispatching decision. Energy efficiency management is implemented to provide diversified services such as internet service, social agency, financial institutions agency and automatic teller machine by fully making use of power information collection and the production information monitoring of intelligent park and enterprise production management. Intelligent service dispatching is implemented by using site monitoring, marketing and service dispatching. 


\section{Functions of Intelligent Power Service System}

Based on strong intelligent grid and modern management concept, intelligent power service system implement the real time interaction of energy flow, information flow and business flow between grid and users by using many technologies such as high grade measuring, high efficient control, high speed communication and quick energy storage, and build a new supply and use power pattern with broad participation of users, prompt response of market, various service modes, optimized resources allocation, efficient and intensive management and win-win cooperation of all parties. We provide the basic diagrammatic sketch which includes sensing unit, interaction terminal, electric power communication network and perceived interaction platform, etc. As shown in Fig. 1.

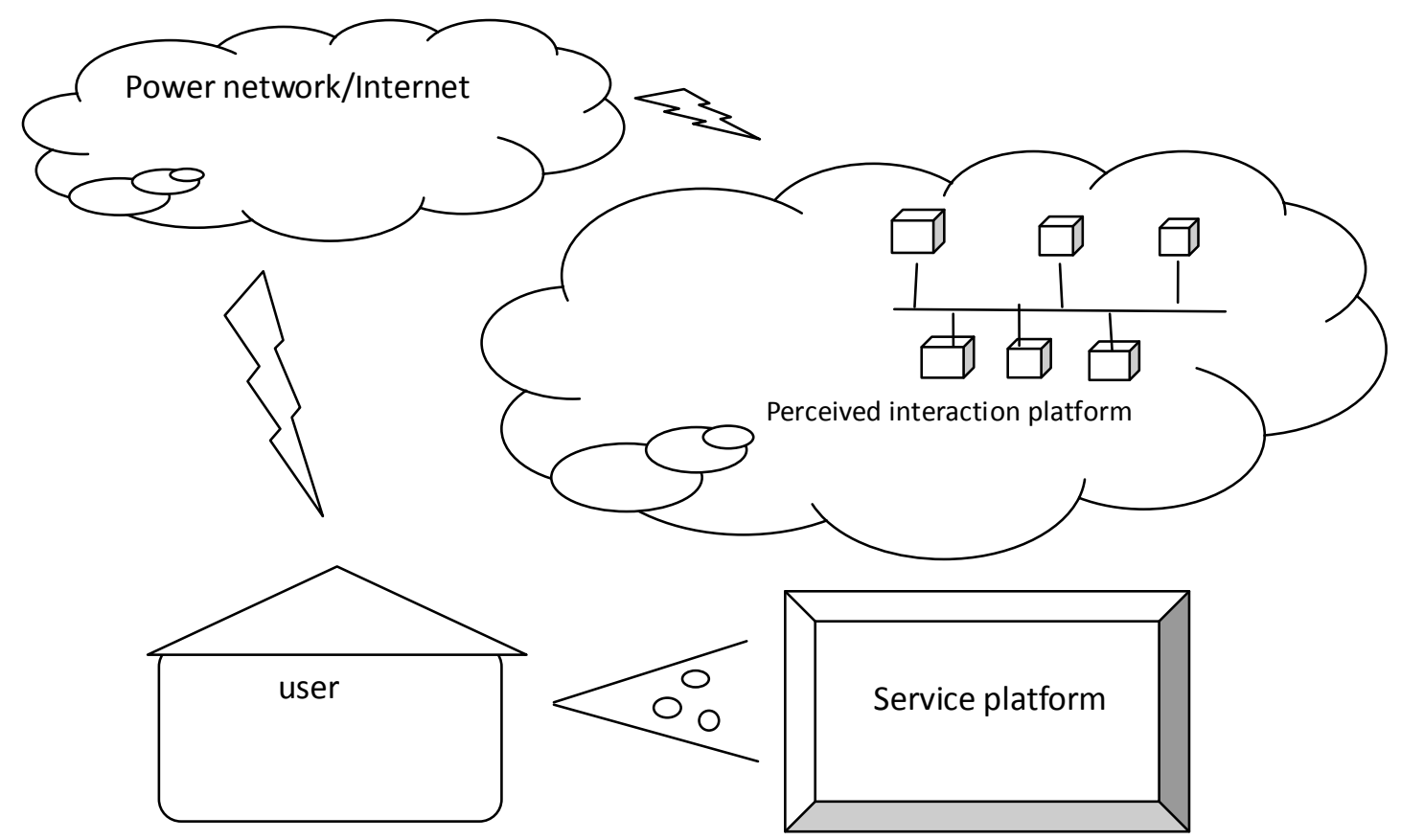

Figure 1. the basic diagrammatic sketch of intelligent power service system

Intelligent power service systemneed meet the following requirements.

It should support access of new energy and equipment. The flexible access, real time motoring and flexible control of distributed generation can be implemented according to intelligent power service system. The system possesses the management and control system, the access standards and practices of grid connected operation and management of distributed generation.

It should response the requirement of using power freely of users. According to the effective information interaction of power supplier and users, users can choose the best energy use plan that users can response to power requirement autonomously and transfer partial load in rush hour to off-peak hours in order to reduce power costs, reduce the peak load of power grid and enhance the operating efficiency of generation and transmission equipment according to the real time price information published by power grid.

It can provide interactive and diversified power service. The personalized and differentiated service requirements should be considered fully, and the bidirectional alternation of energy flow, information flow and business flow is realized. The system provide flexible, customized, various, efficient and convenient services for users, constantly increase service ability to meet the requirements of diversified power services and boost customer satisfaction.

\section{Analysis on Application of Intelligent Power Service System in Power Marketing}

To Control the Power Sales. Scientifically controlling power sales is the first step of the application of intelligent power service system in power marketing. Over a long period in the past, the main control mean of power enterprises in aspect of power sales is manual meter reading in 
order to know the power consumption of users and take appropriate marketing measures because of the underdevelopment of technology. But this control mean must waste a lot of manpower and material resources, and the power sales can not be known in time. In addition, the data obtained by manual meter reading has a time lag which seriously affect the marketing efficiency and effectiveness of power enterprises and can not minimize the economic effect of power enterprises.

To Enrich the Power Marketing Methods. The application of intelligent power service system in power marketing enrich the power marketing methods. As we all know, the power marketing methods are relatively single because of the underdevelopment of technology in the past period. This singe method has bad effect on power marketing and can not help to realize the economic benefit maximum. The following marketing methods are the main marketing methods of power marketing after intelligent power service system is applied in power marketing. The optimization of the program of power business expanding can be implemented according to intelligent power service system in the process of power business expanding that different analysis mode can be adopted for different user, and individual program can be formulated for different user to guarantee the power marketing level.

To Implement Intelligent Control to Power Meters. The intelligent management of power meters can be implemented in intelligent power service system. Over a long period in the past, power enterprises must sent large staffs to examine the meters because of the lower management level and the lower management efficiency of meters. Large economic costs of enterprises is brought by this undeveloped method, and there are many errors caused by manual meter reading which affect the calculation of power and the customer management. With intelligent power service system, enterprises can implement intelligent management for power meters, collect data in time, set price parameter and preset amount and alarm threshold, etc. Enterprises can know the power consumption of users, effectively avoid some stealing power phenomenons and ensure maximum economic efficiency according to the intelligent management for power meters.

To Implement Intelligent Customer Service Dispatch. Intelligent customer service dispatch can be implemented with the help of intelligent power service system. Intelligent power service system can help to collect power information, provide exact location and classification for the abnormal information collected on the site and submit information to service staff who dispatch service personnel to provide service on the site. For the default reporting and emergent default reporting business accepted, the platform can provide ancillary support to analyze the fault point and fault type and sent the service personnel of the best optimal path order to implement the reasonable dispatch of personnel for emergent default reporting, future contribute to improve the customer service dispatch efficiency, increase the customer satisfaction and ensure the quality of power marketing to be the best.

\section{Conclusion}

Intelligent power service system is the informatization foundation of the friendly interaction of power grid and users, and is the key link of building intelligent power service system for power grid company. Intelligent power service system can effectively improve the existing power service, carry out new type intelligent power service and support the implementation of social value added service of the third party. Intelligent power service system is an integration of many technologies such as applications, communication network and sensing measurement whose popularization and application will completely eliminate the information isolated island phenomenon brought by the single intelligent system. The supporting of accesses of intelligent system and equipment contribute to information sharing and business application and will promote the widespread application of internet of things, cloud computing and intelligent services in energy information field. In a word, because the contents involved in power marketing work are large and various, good power marketing effectiveness and good development of power enterprises can not be get if the advanced technology is not adopted in power marketing. 
In this study, intelligent power service system is primarily applied in the power marketing. The ultimate purpose is to further do power marketing work well and bring more economic benefits for power enterprises.

\section{References}

[1] H.Liu, Application of factor analysis in electric power marketing analysis[J]. Electronic Test, 2015.

[2] S.Lin, Practice of Centralized Meter Reading in Power Marketing Management[J]. Science \& Technology \& Innovation, 2014.

[3] C.C Zhang, Electric Power Marketing Customer Archive Management System of Hefei Power Supply Company[J]. Journal of Anhui Electrical Engineering Professional Technique College, 2014.

[4] T Ye, Reflections on the Current Power Marketing Management[J]. Science \& Technology \& Innovation, 2014.

[5] Barton S B, Koski P. Using Ensemble Streamflows for Power Marketing at Bonneville Power Administration[C]// AGU Fall Meeting. AGU Fall Meeting Abstracts, 2014.

[6] Z Ning, Corporate Power,Marketing Reform of News Media,and Public Interest:Comparative Studies on Media Reform Movements in China and North America[J]. Chinese Journal of Journalism \& Communication, 2013.

[7] Y.F Liang, The Theory and Empirical Research on Auxiliary Service Market and the Grid Frequency Control under the Power Marketing Environment[J]. Value Engineering, 2013, 47(3):291-291.

[8] T.B Wang, M.A Yi-Ling and Y.K Cai, et al. Exploration of Promoting Marketing Data Quality by Taking Advantage of Power Marketing Audit Monitoring Management Model[J]. Northeast Electric Power Technology, 2013.

[9] H.J Liu, C.H Zhao and X.U Yan, et al. Analysis on competency structure for power marketing managers based on interpretative structural modeling[J]. Journal of North China Electric Power University, 2013.

[10] W.D Niu, Research on Power Marketing Strategy Based on Intelligent Power Community[J]. Applied Mechanics \& Materials, 2013, 443:253-257.

[11]N Gao, Power Marketing Information Management Strategy[J]. Computer Cd Software \& Applications, 2012.

[12]K.E You-Zhi, Strengthening the Work of Wuhan Electric Power Marketing Contending for Excellence[J]. Equipment Manufacturing Technology, 2012. 